\title{
SARS-CoV-2 precipitated Kasabach-Merritt syndrome in a child with Kaposiform Hemangiendothelioma and acute lymphoblastic leukemia
}

\author{
Vanessa Zarate $^{1}$, Alejandra Cahuata ${ }^{1}$, Roxana Diaz ${ }^{1}$, Kenny Chonlon ${ }^{1}$, Giancarlo \\ Alvarado-Gamarra ${ }^{1}$, and Jesus Dominguez-Rojas ${ }^{1}$ \\ ${ }^{1}$ National Hospital Edgardo Rebagliati Martins
}

September 25, 2021

\begin{abstract}
Kaposiform hemangiendothelioma usually occurs in children under two years of age and develops thrombocytopenia secondary to sequestration of platelets within (Kasabach-Merritt phenomenon) and is complicated by secondary consumption of fibrinogen and clotting factors. SARS-CoV-2 produces cutaneous endothelitis as a direct effect of the presence of the virus and the host inflammatory response. We describe an 8-month-old boy with leukemia and SARS-CoV-2 infection who developed KasabachMerritt phenomenon, coagulopathy, and intestinal involvement. Given the emerging evidence of endothelial and vascular involvement in COVID-19, the development of tests to detect vascular injury may be critical to guide the use of new therapeutic strategies.
\end{abstract}

\section{LETTER TO THE EDITOR}

SARS-CoV-2 precipitated Kasabach-Merritt syndrome in a child with Kaposiform Hemangiendothelioma and acute lymphoblastic leukemia

To the editor: The association between giant hemangioma and thrombocytopenia was described by Haig Kasabach and Katharine Merritt in 1940 [1]. Kasabach Merritt syndrome is usually a rapidly growing vascular anomaly causing consuming coagulopathy, thrombocytopenia, hypofibrinogenemia, D-dimer, microangiopathic hemolytic anemia, prolonged thromboplastin and thromboplastin time; this syndrome is $90 \%$ associated with Kaposi's hemangioendothelioma [2,3]. HEK has an unpredictable course and with visceral infiltration are considered extensive and unresectable lesions, so they have a poor prognosis [4]. We describe an 8-month-old boy with Kasabach Merritt syndrome due to Kaposi's hemangioendothelioma precipitated by COVID-19 infection. According to the mother, 5 days ago he presented fever, rhinorrhea and describes a violaceous lesion in the right dorsal region. RNA testing for SARS coronavirus 2 was performed on a respiratory specimen by RT-PCR and was positive. A $6 \times 7 \mathrm{~cm}$ diameter, indurated, purplish-red lesion with superficial telangiectasias was observed [Figure 1]. Thoracic angiography showed vascular pedicle in the dorsal trajectory related to vascular structures branches of the intercostal 11 and 12 without organ involvement [Figure 2]. Blood tests on the fifth day show severe thrombocytopenia $7000 / \mathrm{mm} 3$, leukopenia $1740 / \mathrm{mm} 3$, and severe neutropenia $130 / \mathrm{mm} 3$, positive C-reactive protein $24.9 \mathrm{mg} / \mathrm{dl}$ and hypoalbuminemia $2.89 \mathrm{~g} / \mathrm{dl}$, elevated prothrombin time $103.48 \mathrm{sec}$, INR 11.45 , d-dimer $15.4 \mathrm{ug} / \mathrm{ml}$, partial thromboplastin time and uncoagulable fibrinogen, ferritin $561.3 \mathrm{ng} / \mathrm{ml}$, receiving platelet transfusions, cryoprecipitate, propanolol and methylprednisolone. After 2 weeks he presented vomiting, abdominal distension, painful abdomen on palpation, with suspicion of intestinal obstruction and underwent surgery, showing abdominal perforation and ending with functional ileostomy. The biopsy of the intestinal segment describes hemorrhagic infarction lesions with foci of ischemic necrosis, without evidence of thrombi. 
The mechanisms of vascular injury in COVID-19 appear to be related to inflammation, endothelial injury and thrombosis [5]. Above all, increased immune responses and cytokine storms cause thrombotic disorders in patients with severe COVID-19, with high levels of d-dimer being found in most patients with COVID-19 [6 - 7]. Acute lymphoblastic leukemia and SARS-CoV-2 infection may be a precipitating factor for vascular complications (Kasabach-Merritt phenomenon) and coagulopathies at the intestinal level.

It should be reported that the observed vascular cutaneous manifestations, should also pay attention in predicting the prognosis of patients with COVID - 19 [8]. Treatment of KM is supportive and prevention of life-threatening complications while addressing the underlying tumor [9]. This condition caused by COVID19 focuses on gastrointestinal decompression, fluid resuscitation, hemodynamic support, surgical resection of necrotic bowel, and restoration of blood flow to the ischemic bowel [10].

SARS-CoV-2 in children with cancer can precipitate the formation of giant vascular lesions with KasabachMerritt phenomenon and the coagulopathy caused requires evaluation of all organs at risk for thrombosis.

\section{CONFLICT OF INTEREST}

The authors of this manuscript certify that they have no affiliations with or involvement in any organization or entity with any financial interest (such as honoraria; educational grants; participation in speakers' bureaus; membership, employment, consultancies, stock ownership, or other equity interest; and expert testimony or patent-licensing arrangements) or nonfinancial interest (such as personal or professional relationships, affiliations, knowledge or beliefs) in the subject matter or materials discussed in this manuscript.

\section{AUTHOR CONTRIBUTIONS}

All persons who meet authorship criteria are listed as authors, and all authors certify that they have participated sufficiently in the work to take public responsibility for the content, including participation in the concept, design, analysis, writing, or revision of the manuscript.

\section{CONSENT TO PARTICIPATE}

The authors of this manuscript certify that informed consent was obtained and signed from the patient's parent/legal guardian to participate in this case report for submission to the journal.

\section{CONSENT TO PUBLISH}

The authors of this manuscript certify that informed consent was obtained and signed from the participant's parent/legal guardian regarding publishing their data and photographs.

\section{REFERENCES}

1. HH K, KK M. Capillary hemangioma with extensive purpura: Report of a case. Am J Dis Child. 1940 May 1;59(5):1063-70.

2. Wang $\mathrm{P}$, Zhou W, Tao L, Zhao N, Chen X-W. Clinical analysis of kasabach-merritt syndrome in 17 neonates. BMC Pediatr. 2014 Jun 11;14:146.

3. Acharya S, Pillai K, Francis A, Criton S, Parvathi VK. Kasabach merritt syndrome: management with interferon. Indian J Dermatol. 2010;55(3):281-3.

4. Drolet BA, Trenor CC, Brandão LR, Chiu YE, Chun RH, Dasgupta R, et al. Consensus-derived practice standards plan for complicated Kaposiform hemangioendothelioma. J Pediatr. 2013;163(1):28591.

5. Roumen - Klappe EM, den Heijer M, van Uum SH, et al. Respuesta inflamatoria en la fase aguda de la trombosis venosa profunda. J Vasc Surg . 2002; 35 ( 4 ): 701-706.

6. Jose RJ, Manuel A. Tormenta de citocinas COVID-19: la interaccion entre la inflamacion y la coagulacion. Lancet Raspir Med. 2020; 8 (6): e46 - e47.

7. Zhou F, Yu T, Du R y col. Curso clinico y factores de riesgo para la mortalidad de adultos en pacientes con COVID-19 en Wuhan, China: un estudio de cohorte retrospectivo. Lancet. 2020; 395 (10229): 1054-1062. 
8. Afsaneh Sadeghzadeh-Bazargan MD, Mahdi Rezai MD. Skin manifestations as potential symptoms of diffuse vascular injury in critical COVID-19 patients. J Cutan Pathol. 15 de junio de 2021: 10.1111 / cup.14059.

9. Priya Mahajan, Judith Margolin. Kasabach-Merritt Phenomenon: Classic Presentation and Management Options. Clin Med Insights Blood Disord. 2017 Mar 16; doi:10.1177/1179545X17699849.

10. Balraj Singh, Ashesha Mechineni. Acute Intestinal Ischemia in a Patient with COVID-19 Infection. Korean J Gastroenterol 2020; 76(3): 164-166. https://doi.org/10.4166/ kjg.2020.76.3.164.

Figure 1: Evolving dermatological images of the vascular lesion.

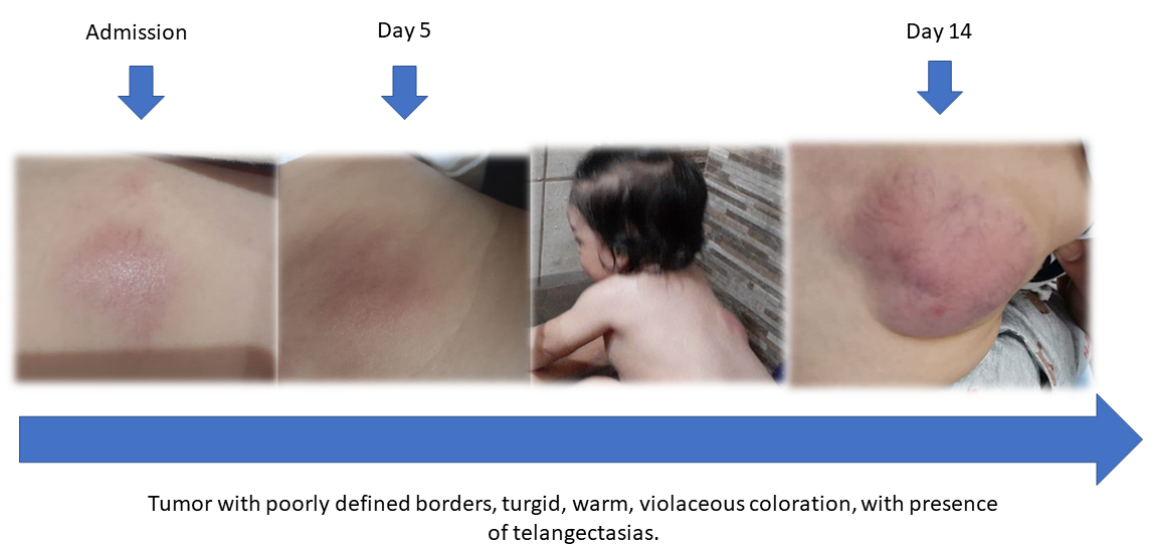

Figure 2: Thoracic Tomography

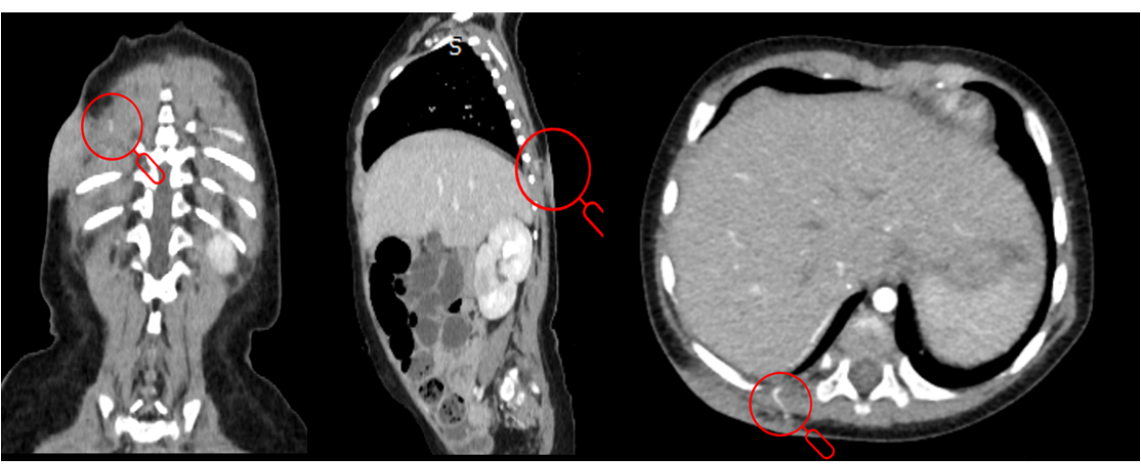

The images describe a soft tissue lesion in the lower right posterolateral thoracic wall measuring $11 \mathrm{~mm}$ thick and $5.9 \mathrm{~cm}$ in greatest diameter, related to vascular structures of the intercostal branches 11 and 12 on the same side, best represented in arterial phase. 